\title{
Microbiota conjuntival de cães hígid os e com afecções oftálmicas
}

\author{
Conjunctival microorganisms from healthy dogs and with eye diseases
}

\begin{abstract}
Luana Gabriela Ferreira dos Santos, Arleana do Bom Parto Ferreira de Almeida, Maria Cristina da Silva, Juçara Tinasi de Oliveira, Valéria Dutra \& Valéria Régia Franco Sousa
\end{abstract}

\begin{abstract}
RESUMO
A conjuntiva é considerada a membrana mais exposta do organismo, possui grande importância na dinâmica ocular, mantém relação direta com o meio externo e atua na proteção mecânica do bulbo ocular. Existem micro-organismos que ajudam na sua defesa e, juntamente com fatores humorais, inibem o estabelecimento de agentes patogênicos. O objetivo deste trabalho foi avaliar a microbiota conjuntival de cães hígidos e com afecções oculares. Foram avaliados 100 cães (50 com afecção ocular e 50 hígidos), com ou sem raça definida, oriundos do atendimento clínico-médico do Hospital Veterinário da Universidade Federal de Mato Grosso. Após a contenção adequada dos animais, foi realizada limpeza ocular e colheita de material do saco conjuntival inferior, com auxílio de suabes estéreis, para isolamento e identificação de bactérias e fungos. Os resultados obtidos indicam que a bactéria de maior ocorrência, dentre os animais hígidos, foi Bacillus spp., enquanto o Staphylococcus intermedius foi mais observado nas afecções oculares. O fungo de maior ocorrência foi Candida spp. O estudo apontou que houve variação da microbiota conjuntival devido às afecções oculares, sendo observada diferença estatisticamente significativa entre os animais hígidos e oftalmopatas quanto à presença de Bacillus sp. e Escherichia coli.
\end{abstract}

Descritores: cão, microbiota conjuntival, afecção ocular.

\section{ABSTRACT}

The conjunctiva is considered the most exposed membrane of the body, has great importance in the eye's dynamic, maintains a direct relationship with the external environment and performs mechanical protection of the eyeball. There are microorganisms that help in its defense and associated to humoral factors inhibit the colonization of pathogens. The objective of this study was to evaluate the conjunctival microorganisms from healthy and diseased dog's eyes. One hundred dogs were analyzed (50 diseased and 50 healthy), with or without defined breed, from the clinical care of the Veterinary Hospital at Federal University of Mato Grosso. After the animals proper restrain, the eyes were cleaned around and material collected from the conjunctival bag with sterile swabs, for further isolation and identification of bacteria and fungi. The results showed Bacillus sp., as the bacteria with greater occurrence in healthy animals and Staphylococcus intermedius as the most observed in diseased eyes. Candida sp. was the fungus whit higher occurrence. The study pointed out that there was a variation in the conjunctival microbiote, due to eye diseases, being observed significant statistically difference between healthy animals and ophthalmic disturbs in the presence of Escherichia coli and Bacillus sp.

Keywords: dog, conjunctival micobiot, eye disease. 


\section{INTRODUÇÃO}

A conjuntiva possui grande importância na dinâmica lacrimal, na proteção imunológica do olho, nos movimentos oculares e na cicatrização corneana, agindo como barreira à entrada de micro-organismos, patogênicos ou não [1,6]. A superfície ocular é colonizada por microbiota bacteriana que ajuda na sua defesa e, juntamente com fatores humorais, inibe o estabelecimento de micro-organismos patogênicos. Entretanto, podem ocorrer mudanças, principalmente pela diminuição da imunidade local e sistêmica do animal, bem como o contato com micro-organismos virulentos [15].

As conjuntivites, ceratites e endoftalmites podem ameaçar a integridade do olho e produzir destruição tecidual significativa. O conhecimento do agente causador, do processo e progressão da doença, bem como estabelecimento de tratamento coerente e eficaz influencia na evolução e prognóstico da doença [15].

A bibliografia menciona que, em 70 a $90 \%$ dos cães clinicamente saudáveis, é possível isolar bactérias do saco conjuntival. Dentre estas, as mais comuns são as aeróbias gram-positivas, podendo ocorrer também bactérias gram-negativas, anaeróbias e fungos [6]. No entanto, tais agentes também foram isolados da microbiota ocular normal $[1,8,11,13]$.

A grande diversidade de micro-organismos existentes na microbiota ocular canina e a eventual patogenicidade dos mesmos torna importante novos estudos que venham ajudar no tratamento adequado das doenças oculares. Sendo assim, o objetivo deste trabalho é avaliar a microbiota conjuntival de cães hígidos e com afecções oculares, atendidos no Hospital Veterinário da Universidade Federal de Mato Grosso (HOVET-UFMT).

\section{MATERIAIS E MÉTODOS}

No período de janeiro a novembro de 2007, foram avaliados 100 cães (50 com afecção ocular e 50 hígidos), com ou sem raça definida, escolhidos aleatoriamente no atendimento clínico-médico do HOVET-UFMT. Previamente à colheita, os cães foram avaliados através de exame físico, para a observação de possíveis alterações sistêmicas concomitantes.

Após a contenção adequada dos animais, foi realizada a limpeza das pálpebras com gaze umedecida em solução fisiológica, retirando-se todo o excesso de secreção e sujidade ocular externa. As amostras foram colhidas do saco conjuntival com auxílio de "swabs" de algodão hidrófilo estéril, a seguir colocados em tubos contendo $5,0 \mathrm{ml}$ de caldo infusão de cérebro e coração (BHI), e remetidos ao Laboratório de Microbiologia do HOVET-UFMT, para isolamento bacteriano e fúngico.

Primeiramente, os "swabs" foram incubados no meio $\mathrm{BHI}$, em aerofilia, a $37^{\circ} \mathrm{C}$, por 18 horas, para um pré-cultivo. Em seguida, o material foi semeado em Ágar Sangue Ovino 5\%, Ágar MacConkey e Ágar Sabouraud e incubados em aerofilia a $37^{\circ} \mathrm{C}$, por $24-48$ horas. Os isolados foram identificados de acordo com suas características tintoriais, morfológicas e bioquímicas [12].

A análise estatística dos cães sem e com afecções oculares foi realizada pelo teste de Qui-quadrado, através do programa Epi Info 3.3.2., sendo considerado estatisticamente significativo $\mathrm{p} \leq 0,05$.

\section{RESULTADOS}

Dos 100 cães pesquisados, 56 eram machos, 44 fêmeas, encontrando-se na faixa etária de menos de um ano 25 cães, entre um a quatro 37 cães, quatro a oito 20 cães e maior do que oito anos, 18 cães, sendo os sem raça definida os mais frequentes, com 41 animais, seguidos de Pastor Alemão (13), Boxer, Pit Bull e Pinscher (7), Poodle (6), Basset Hound (5), Dálmata (4), Teckel (3), Maltês, Cocker (2) e Schnauzer, Lhasa Apso e Sharpei (1).

Dos duzentos olhos estudados, todos (100\%) apresentaram crescimento de micro-organismos. No presente estudo, os animais hígidos apresentaram, em sua microbiota, bactérias como: Bacillus spp. (31,28\%), Staphylococcus intermedius (20,85\%), Escherichia coli $(15,95 \%)$, S. aureus $(8,58 \%)$, Proteus mirabilis $(5,52 \%)$, Enterobacter aerogenes (3,68\%), Micrococcus sp. e Pseudomonas aeruginosa em 1,84\% dos cães. Os agentes fúngicos isolados foram Candida spp. $(8,58 \%)$ e Malassezia pachydermatis $(1,84 \%)$ nos cães clinicamente sadios.

A microbiota conjuntival de cães com afecções oculares constituiu-se de fungos, bactérias grampositivas e bactérias gram-negativas, como descritas na Tabela 1. Candida spp. foi encontrada em 50\% dos cães com tumoração palpebral. Malassezia pachydermatis foi isolada em cães com alterações oftálmicas. Observou-se diferença estatisticamente significativa entre os animais hígidos e oftalmopatas quanto à presença de Bacillus sp. e Escherichia coli. 


\section{DISCUSSÃO}

As bactérias isoladas nos animais hígidos, como Bacillus spp. e Staphylococcus intermedius são consideradas comuns ao saco conjuntival $[6,16]$. A microbiota conjuntival mantém-se estável em animais clinicamente sadios, isentos de afecções oculares ou sistêmicas, sendo que a destruição da microbiota normal está associada ao uso prolongado de antimicrobianos tópicos, podendo resultar em crescimento excessivo de bactérias e/ou fungos [1].

A análise da microbiota conjuntival aeróbica de cães sadios encontrou 326 cepas de bactérias, sendo $73,23 \%$ cocos gram-positivos, $15,02 \%$ bactérias gramnegativas e 11,66\% bacilos gram-positivos, sendo mais prevalentes estafilococos coagulase-negativos $(43,25 \%)$ e Staphylococcus aureus $(10,12 \%)$ [14].

Outros estudos isolaram bactérias a partir do saco conjuntival de cães hígidos em percentagens semelhantes ao presente estudo. Em 30,16\% dos cães, foi isolado Staphylococcus aureus, enquanto Bacillus spp. em 26,98\% dos casos analisados, o que concorda com os resultados obtidos no estudo para a identificação de bactérias isoladas de animais hígidos [7].

Nos cães que apresentavam afecções oculares, as bactérias mais frequentemente isoladas foram Staphylococcus intermedius (26,19\%), Bacillus spp. $(20,23 \%)$ e $S$. aureus $(13,69 \%)$. Alguns autores encontraram os mesmos micro-organismos em cães com conjuntivite, blefarite, dacriocistite e úlcera corneana $[8,16]$. No entanto, segundo a bibliografia essas bactérias fazem parte da microbiota ocular normal canina
[6]. Este fato ressalta o descrito por pesquisadores, que podem ocorrer mudanças nesta microbiota relacionada à imunidade local e sistêmica do animal promovendo a infecção ocular por micro-organismos patogênicos [15].

Os micro-organismos mais isolados foram os do gênero Staphylococcus, em alterações oculares, como entrópio, blefarite, protrusão da glândula nictitante e catarata, concordando com outros estudos $[8,15]$. Estudos comprovam ser comum verificar a presença destes agentes nestes tipos de afecção, pois são considerados como presentes na microbiota da pele de cães [1].

A conjuntivite, afecção ocular mais frequentemente observada em cães, apresentou isolamento de bactérias gram-positivas e bactérias gram-negativas como Staphylococcus. intermedius (24,07\%), Bacillus spp. (19,44\%), S. aureus $(15,74 \%)$, Proteus mirabilis $(10,18 \%)$ e Enterobacter spp. (8,33\%). Staphylococcus aureus já foi obtido em maiores porcentagens em alguns trabalhos, o que mostra que diferentes espécies de estafilococos podem ser encontradas nos olhos com afecções [15].

Proteus mirabilis é encontrado em animais saudáveis, sendo comumente causador de infecção urinária, podendo ser isoladas de diversos locais, principalmente em indivíduos imunossuprimidos [3]. Neste estudo, esta bactéria foi isolada tanto em animais hígidos quanto em doentes, concordando com o referido autor e também com outro autor, ao estudar a microbiota conjuntival de macacos-prego [5].

Tabela 1. Afecções oculares e frequência do principal agente isolado em cães atendidos no Setor de Clínica Médica do Hospital Veterinário da Universidade Federal de Mato Grosso, no período de janeiro a novembro de 2007.

\begin{tabular}{lcc}
\hline \multicolumn{1}{c}{ Afecção ocular } & Agente & $\%$ \\
\hline Conjuntivite (28) & Staphylococcus intermedius & 24,13 \\
Blefarite (3) & Staphylococcus intermedius & 28,5 \\
Catarata (6) & Staphylococcus intermedius & 42,10 \\
Protusão de terceira pálpebra (3) & Staphylococcus aureus & 25 \\
Entrópio (3) & Staphylococcus aureus & 30 \\
Ectrópio (1) & Proteus mirabilis & 60 \\
Tumor palpebral (2) & Candida sp. & 50 \\
Ceratite ulcerativa (1) & Bacillus sp. & 100 \\
Obstrução ducto nasolacrimal (2) & Staphylococcus intermedius & 66,66 \\
Glaucoma (1) & Bacillus sp. & 100 \\
\hline
\end{tabular}


Nos casos de cães com obstrução do ducto nasolacrimal, a bactéria mais observada foi o Staphylococcus intermedius $(66,66 \%)$, sendo que as manifestações clínicas associadas às afecções do sistema lacrimal são causadas pela ação das bactérias presentes nesta região e incluem epífora, secreção conjuntival mucopurulenta, edema com hiperemia da região do canto ventro-medial, manchas pronunciadas suboculares sobre as lactoferrinas do filme lacrimal e ainda tumorações da face e região nasal [6].

Em $100 \%$ dos animais com ceratite ulcerativa, foi constatada a presença de Bacillus spp., o que concorda com resultados obtidos no estudo para a identificação de bactérias isoladas de úlceras de córnea em cães $[6,10]$. Apesar de não apresentar alteração das membranas oculares externas, como conjuntiva, córnea e pálpebras, todos os cães com glaucoma apresentaram positividade de crescimento bacteriano, sendo o Bacillus spp. o agente isolado. Como afirmado em outros estudos, este agente é comum na microbiota normal do saco conjuntival, característica encontrada nestes cães.

Estatisticamente, foi observada diferença entre os cães estudados quanto à presença dos agentes Bacillus sp. e Escherichia coli, com maior presença nos animais sadios. No entanto, a bibliografia descreve uma frequência maior de Escherichia coli nos cães com afecções oculares, discordando do obtido neste estudo [16], já que é um agente causador de oftalmopatias com contaminação direta ou disseminação hematógena [4].

Os agentes fúngicos isolados foram Candida spp. $(8,58 \%)$ e Malassezia pachydermatis $(1,84 \%)$ nos cães clinicamente sadios. Em alguns trabalhos, Candida spp., foi a levedura mais observada em humanos com conjuntivite [15]. No presente estudo, tal levedura foi encontrada em $50 \%$ dos cães com tumoração palpebral. Apesar de não ter sido isolada em cães com alterações oftálmicas, a M. pachydermatis tem sido descrita como importante no agravamento dos quadros de ceratite ulcerativa [11]. A presença de fungos na conjuntiva pode representar constante ameaça aos olhos em condições de baixa imunidade [9].

Em 35\% dos animais com afecções oculares, foram observadas doenças sistêmicas, as mais comuns foram ehrlichiose, cinomose e leishmaniose. Essas doenças, além de causarem alterações oculares, são responsáveis pelo comprometimento da imunidade animal e, consequentemente, pela instalação de várias doenças oportunistas, inclusive de complicações oculares [2].

$\mathrm{O}$ isolamento dos mesmos micro-organismos tanto nos cães hígidos quanto nos com afecções oculares, reforça o descrito por inúmeros autores de que a mudança nas condições normais da superfície ocular e da imunidade do animal pode tornar as bactérias oculares residentes potencialmente patogênicas, levando a danos graves aos tecidos oculares [9]. É valido citar que a Candida spp. também fora isolada em olhos na mesma condição em estudos semelhantes, nos cães que apresentavam tumor palpebral, foi verificada a ocorrência de $50 \%$ deste micror-oganismo, embora a presença deste agente em afecções oculares seja mais frequentemente verificada em equinos do que em cães [1].

\section{CONCLUSÃO}

Com base nos resultados obtidos no presente estudo, conclui-se que, das bactérias isoladas houve predominância de $S$. intermedius em animais com afecção ocular e Bacillus spp. nos animais hígidos. Dos fungos isolados, o mais frequente foi Candida spp.

\section{REFERENCIAS}

1. Andrade A.L., Stringhini G., Bonello F.L., Marinho M. \& Perri S.H.V. 2002. Microbiota conjuntival de cães sadios da cidade de Araçatuba, São Paulo. Arquivo Brasileiro de Oftalmologia. 65: 323-326.

2. Brito F.L.C., Alves L.C. \& Laus J.L. 1998. Manifestações oculares na leishmaniose visceral canina - revisão. Clínica Veterinária. 64: 68-74.

3. Carter G.R. 1998. Fundamentos de bacteriologia e micologia veterinária. 3.ed. São Paulo: Roca, 249p.

4. Fochesatto G.Q., Petermann A.G., Junior A.G., Andrade G.V.O. \& Ramos A.R.B. 2002. Endoftalmite bacteriana endógena pós-colectomia - Relato de Caso. Arquivo Brasileiro de Oftalmologia. 65: 7-53.

5. Galera P.D., Ávila M.O., Ribeiro C.R. \& Santos F.V. 2002. Estudo da microbiota da conjuntiva ocular de macacos pregos (Cebus apella - Linnaeus, 1758) e macacos bugio (Alouatta caraya - Humboldt, 1812), provenientes do reservatório de Manso-MT, Brasil. Arquivos do Instituto Biológico. 69: 33-36.

6. Gelatt K.N. 2003. Manual de Oftalmologia Veterinária. 2. ed. São Paulo: Manole, p.594 
7. Haghkhah M., Sarchahi A.A. \& Molazem M. 2005. Conjunctival flora in normal dogs. Online Journal of Veterinary Research. 2: 79-83.

8. Murphy J.M., Lavach J.D. \& Severin G. 1978. A Survey of conjunctival flora in dogs with clinical signs of external eye disease. Journal of the American Veterinary Medical Association. 172: 66-68.

9. Petrocinio R.R., Colombini G. \& Mandarino J.R. 2006. Perfil da microbiota conjuntival em pacientes HIV positivos. Revista Brasileira de Oftalmologia. 65: 6-73.

10. Prado M.R. 2006. Identificação e susceptibilidade antimicrobiana de bactérias isoladas de úlceras de córnea em cães. Arquivo Brasileiro de Medicina Veterinária e Zootecnia. 58: 1024-1029.

11. Prado M.R., Rocha M.F.G., Brito E.H.S., Girao M.D., Monteiro A.J. \& Sidrim J.J.C. 2004. Higher incidence of Malassezia pachydermatis in eyes of dogs with corneal ulcer than in healthy dogs. Veterinary Microbiology. 100: 115120.

12. Quinn P.J., Carter M.E., Markey B. \& Carter G.R. 1994. Clinical Veterinary Microbiology. London: Wolfe, pp.400-401.

13. Samuelson D.A., Andresen T.L. \& Gwin R.M. 1984. Conjunctival fungal flora in horses, cattle, dogs and cats. Journal of the American Veterinary Medical Association. 184: 1240-1242.

14. Silva P.A.R. 2006. Microbiota conjuntival aeróbica de cães sadios no Distrito Federal. http://www.unb.br/fs/dd_pars.htm. Acessado em 17/04/06.

15. Uesugui E., Cypel M.C., Atique D., Goulart D.G., Gallucci F.R., Nishiwaki M.C \& Dantas P.E.C. 2002. Identificação laboratorial dos patógenos oculares mais frequentes e sua suscetibilidade in vitro aos agentes microbianos. Arquivo Brasileiro de Oftalmologia. 65: 339-342.

16. Wang L., Pan Q., Zhang L., Xue Q., Cui J. \& Qi C. 2008. Investigation of bacterial microorganisms in the conjunctival sac of clinically normal dogs and dogs with ulcerative keratitis in Beijing, China. Veterinary Ophthalmology. 11: $145-149$. 